\title{
Treatment of recurrent esophageal stricture with an insulated-tip electrosurgical knife and mitomycin C
}

An 82-year-old woman presented with dysphagia due to a refractory esophageal stricture. The stricture was thought to have been caused 2 years previously after hospitalization for a hip fracture and prolonged nasogastric tube placement at a subacute care facility. Numerous attempts at stricture dilation, initially every 2 weeks, had been made at another institution using a hydrostatic balloon and an esophageal stent, which was later removed because of complications.

At our center, the patient underwent upper gastrointestinal (GI) endoscopy under general anesthesia, during which a severe benign-appearing intrinsic stenosis (4-mm wide and $1-\mathrm{cm}$ long) that prohibited passage of the endoscope was encountered $31 \mathrm{~cm}$ from the incisors ( $\vee$ Video 1). The stenosis was incised using an insulated-tip electrosurgical knife along the aspect opposite to the aorta. Balloon dilation was performed to a diameter of $15 \mathrm{~mm}$ before the stenosis was traversed and a 4-cm hiatus hernia was noted. The remainder of the upper Gl endoscopy was normal.

Repeat balloon dilation to $15 \mathrm{~mm}$ was then performed. The upper $\mathrm{Gl}$ endoscope was removed and an overtube was advanced to the level of the stricture to minimize mucosal contact with mitomycin C. A gauze soaked with $1 \mathrm{~mL}$ of mitomycin $C$ solution $(0.4 \mathrm{mg} / \mathrm{mL})$ was delivered to the level of stricture with a rat-toothed forceps that was fed through the endoscope ( $\mathbf{F i g . 1}$ ). The gauze was applied to the level of the stenosis for 3 minutes and this was followed by a second 2-minute treatment.

The patient was discharged home on a full liquid diet for 2 days followed by soft diet for 2 days. She was seen in clinic 7 months later with no recurrent symptoms.

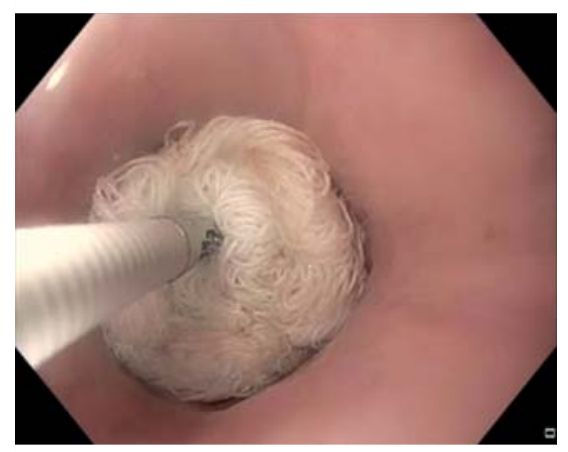

- Fig. 1 Direct application of a gauze soaked with mitomycin $C$ to the level of the stricture after insulated-tip electrosurgical knife incision had been performed.

Esophageal stricture due to prolonged nasogastric tube placement has been previously reported [1]. Data on the use of topical mitomycin C for esophageal strictures are limited, but similar techniques have been shown to be safe and effective in children with strictures due to caustic injury or after repair of esophageal atresia [2-5].

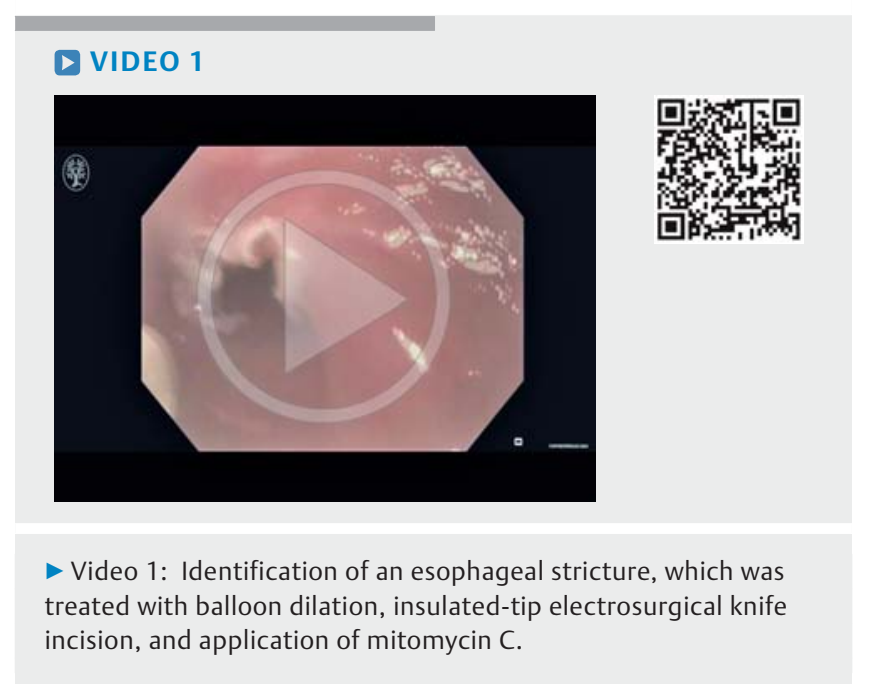




\section{References}

[1] Yoon YS, Kim JY, Lee KJ et al. Balloon dilatation for an esophageal stricture by longterm use of a nasogastric tube: A case report. Ann Rehabil Med 2014; 38: 581 - 584

[2] El-Asmar KM, Hassan MA, Abdelkader HM et al. Topical mitomycin $C$ application is effective in management of localized caustic esophageal stricture: A double-blinded, randomized, placebo-controlled trial. J Pediatr Surg 2013; 48: 1621 - 1627
[3] El-Asmar KM, Hassan MA, Abdelkader HM et al. Topical mitomycin $C$ can effectively alleviate dysphagia in children with long-segment caustic esophageal strictures. Dis Esophagus 2015; 28: 422-427

[4] Machida H, Tominaga $\mathrm{K}$, Minamino $\mathrm{H}$ et al. Locoregional mitomycin $\mathrm{C}$ injection for esophageal stricture after endoscopic submucosal dissection. Endoscopy 2012; 44: $622-625$

[5] Rustagi T, Aslanian HR, Laine L. Treatment of refractory gastrointestinal strictures with mitomycin C: A systematic review. J Clin Gastroenterol 2015; 49: 837-847

\section{Bibliography}

DOI http://dx.doi.org/10.1055/s-0042-122141 Endoscopy 2017; 49: E68-E69

(c) Georg Thieme Verlag KG

Stuttgart · New York

ISSN 0013-726X 